\title{
LANGUAGE LEARNING AND ENJOYMENT OF STEM STUDENTS STUDYING JAPANESE
}

\author{
Junko Winch
}

\section{doi: 10.18355/PG.2016.5.2.246-270}

\begin{abstract}
In the UK, government policy texts highlighted the notion of enjoyment in 2003 and 2008. 13 years have passed and those who received the education of learning and enjoyment in primary schools are now undergraduate students or older. Has this new generation successfully brought up with learning and enjoyment? This study investigates if the Science, Technology Engineering and Medicine (STEM) majoring undergraduate students who studied Japanese in the Institution-Wide Language Provision (IWLP) context enjoy Japanese language learning. This study is a joint research project between two British universities in London. Questionnaires were used to generate the data. The participants were STEM students who were studying Japanese in the 2015/2016 academic year. The results showed that one in five students have already interests in Japanese culture and Japan before they study, which relates to their enjoyment of language learning to motivation. Furthermore, the majority of the STEM students answered that they enjoyed Japanese language learning and their experience of flow was also confirmed. These 246 results indicate that people's general assumption that all learning is grim and unpleasant is not true and these assumptions can be changed, which may lead to establish language learning as a leisure activity such as games, shopping or hobbies. As an implication for the professional practices, language teachers are encouraged to be familiar with the concept of enjoyment and flow so that they can manipulate and invoke flow their students' enjoyment.
\end{abstract}

\section{Key words}

enjoyment, Institution-Wide Language Provision (IWLP), Japanese language teaching, STEM students

\section{Introduction}

In this section, Institution-Wide Language Provision (IWLP), Science, Technology Engineering and Medicine (STEM) and the background of this study are explained.

This study concerns IWLP, which is defined 'typically comprises elective language course units taken from academic credit and language courses studied in addition to and alongside a student's degree programme' (Association of University Language Centre (AULC), 2016: 2). IWLP works well for both students and language teachers. From students' perspectives, IWLP has allowed Non-language major undergraduate students to study languages on accredited or non-accredit basis. For those who are involved in

Slavonic Pedagogical Studies Journal, ISSN 1339-8660, Volume 5 Issue 2, September 2016 
language teaching, IWLP has benefited to increase the number of nonlanguage major students' interest to language study and therefore it promotes the study of language.

This study also focuses on STEM students. The reason why STEM is highlighted in this study is because it is claimed that STEM and non-STEM subjects have different disciplines and argue that these differences affect their teaching and learning (Neumann - Parry - Becher, 2002: 119). According to Neumann et al. (2002), disciplines are broadly categorised into four, that is, hard pure, soft pure, hard applied and soft applied. Physics and chemistry are categorised in 'hard pure', history and anthropology are examples of 'soft pure'. Engineering typifies a 'hard applied' discipline, whereas education and management studies are examples of 'soft applied' discipline. The differentiation between 'hard' or 'soft' in the 'pure' category is broad whether the emphasis on quantitative (hard) emphasis or qualitative (soft) (Neumann et al., 2002: 406) and whether the knowledge is concerned with universals or with particulars (Neumann et al., 2002: 406), etc. Furthermore, the objective of test assessment in the hard disciplines is knowledge acquisition, whereas that of soft disciplines is the level of sophistication of understanding and interpretation and judgement (Young, 2010). Differences between 'pure' and 'applied' is that 'applied' is 'drawing on hard pure knowledge and application' (Young, 2010) of products, technique or professional practices. Imperial College London is a STEM university in the UK, whose students consists of hard pure and hard applied disciplines based on Neumann's et al. (2002) classification.

This study explores STEM students' Japanese language learning and enjoyment at Imperial College London and Kings College London in 2016, where Japanese is taught in an IWLP context.

Imperial College London's IWLP is called Imperial Horizons, which is offered by the Centre for Language, Culture and Communication. The students who took Imperial Horizons have increased over the last five years. More than 4,000 undergraduate students enrolled in the academic year 201415 which is almost half of the undergraduate population. Compared to the academic year 2012-13 when they launched the Horizon's program, it had approximately 2,000 undergraduate students.

Imperial Horizons offers four areas of study to undergraduate students, i.e. languages and global citizenship, business and professional skills, global challenges and science, culture and society. Language and global citizenship offers ten languages including Japanese. A total of approximately 300 undergraduate students were studying Japanese as either credit or non-credit bearing basis in four levels (between level 1, which is complete beginners and level 4 being more advanced). The courses were taught over two terms (autumn and spring term), in two-hour slots on a weekly basis (4:00-6:00pm) between Monday and Thursday for 19 or 20 weeks. The majority of the participants of this study are undergraduate students from the Horizons program.

Imperial College London also offers language evening classes, which are open to all Imperial College staff and members of the public. The evening 
classes consist of two programmes, the main programme and the intensive summer term programme. The former is taught between October and March in two-hour slots (6:00-8:00pm) between Monday and Thursday on a weekly basis for 19 or 20 weeks. The latter is taught between May and June in twohour slots (6:00-8:00pm) between Monday and Thursday on twice a week for 8 weeks. Participant students of this study also include both main programme and the intensive summer term programme classes.

King's College London's (KCL) Modern Language Centre offers 26 languages and over 8,000 students take part in the language classes each year. They operate 10 weeks' courses in three terms, Autumn term (October to December), Winter term (January to March) and Spring term (April to June). The participants in this study were from Winter term and were taught for 90 minutes on a weekly basis for 10 weeks. The participants consisted of both undergraduate students who are studying STEM subjects and members of public, majority of whom previously studied STEM subjects.

\section{Japanese language learning, enjoyment and flow Why STEM students study Japanese?}

Having taught Japanese language in an IWLP context at four different British universities over the past eight years, the researcher has noticed a tendency that more STEM major students study Japanese than non-STEM subjects. The researcher's colleague had also made similar comment. This forms the initial research question, 'Why STEM major students study Japanese?'

248 According to AULC, 'the relative popularity of Japanese' (AULC, 2016: 6) was reported and 'there had been an increase in the number of students taking Japanese' (AULC, 2016: 6). However, this report did not give details on why Japanese is experiencing an increased uptake.

Taking note that studying another language in addition to STEM subject requires student's commitment, studying Japanese may put students under extra academic pressure and work such as memorising vocabulary, phrases, sentence structures, etc. for assessment. Therefore, the hypothesis was created that STEM major students study Japanese because they enjoy learning it. This hypothesis is a contradiction from general assumption that 'all learning is accompanied with pain' (Davidson, 1990: 201) and 'at present... -schools, officers, factories are organised around the assumption that the serious work is grim and unpleasant' (Csikszentmihalyi, 1975: 1). However, STEM major students must truly enjoy learning Japanese otherwise they would lose interest and drop out. Then, what is the enjoyment that STEM students experience, disregarding these general assumptions?

\section{Enjoyment}

Definition of enjoyment

In this section, enjoyment is defined by comparing enjoyment and pleasure, although enjoyment and pleasure are synonyms and used almost exchangeable in daily life. Pleasure seems to be used in more psychological terms and, according to Csikszentmihalyi (1977), the definition of pleasure is 
'the satisfaction of basic needs - hunger, sex and so forth... in the present model, it does not require the use of complex skills' (Csikszentmihalyi, 1977: 54). Csikszentmihalyi (1977) points out a pleasure/enjoyment continuum ranging from repetitive, automatic acts (chewing gum) to complex activities which requires the full use of person's physical and intellectual potential. Based on Csikszentmihalyi's (1977) notion of this 'pleasure/enjoyment continuum, enjoyment in this paper can be defined as non-repetitive automatic acts and it involves with more complex activities which requires the full use of person's physical and intellectual potential. In addition to this, Blunsdon et al. (2003) definition of enjoyment can also be added: 'enjoyment is sometimes called "interest" or "expressed liking", (Blunsdon et al., 2003: 44). In order to assess STEM students experience enjoyment, following two questions are asked to analyse students' data: 1) Do students mention any comments associated with interest and express their liking? 2) Do students mention any comments related to their intellectual challenge that requires full use of their intellectual potential?

High Arousal Positive states (HAP) and Low Arousal Positive states (LAP) Enjoyment consists of high and low arousal positive states (Tsai et al., 2006). High Arousal Positive states (HAP) associates with enthusiastic, excited and energetic whereas Low Arousal Positive states (LAP) is associated with calm, relaxed and serene (Tsai et al., 2006: 290). Another HAP associated emotion in addition to enthusiastic, excited, energetic is 'joy' (Kuppens, 2008: 1054) and two LAP associated emotions in addition to calm, relaxed serene is content (Kuppens, 2008: 1054) and 'at ease' (Kuppens, 2008: 1057). This means that enjoyment is perceived differently by individuals. In other words, 'for some individuals feeling enjoyment usually implies feeling excited and enthusiastic, whereas for others feeling enjoyment usually implies feeling relaxed and at ease' (Kuppens, 2008). The cause of these individuals difference in feeling enjoyment is culture. According to Tsai et al. (2006), 'individuals from individualist culture (e.g. American, British, Australian culture, etc.) seem to prefer and value HAP (e.g. enthusiastic, excited, energetic) and individualist from collectivist culture (e.g. Chinese and other East Asian cultures) seems to prefer and value LAP (e.g. calm, relaxed, serene) (Tsai et al., 2006). Individualist culture is defined as 'the tendency to place individual over group concerns' (Tsai et al., 2006: 290), and collectivist culture as 'the tendency to place group over individual concerns' (Tsai et al., 2006: 290). The current learning environment became globalized and university students consist of both individualist and collectivist and the students in this study also include both cultures. Usually, in case of a UK context, majority of home (UK) students may prefer individualist culture and majority of international students may prefer a collectivist culture. Therefore, it is essential that language teachers invoke both HAP and LAP to meet students' preference and requirement from both cultures. Whether STEM students experience either HAP or LAP is part of the investigation of students' enjoyment. 
Enjoyment also consists of two emotions, which are called trait emotions and state emotions (Goetz et al., 2006). 'Trait emotions are built over time' (Lumby, 2011: 7) and are experiences of cumulative enjoyment. 'State emotions are experience in the present, the current enjoyment' (Lumby, 2011: 7). According to Blunsdon et al.'s (2003) study, 'students are more willing to act on their feeling for the moment'...enjoyment is experienced at the moment, while learning often occurs over a long period of time and one's appreciation of the learning experience (cognition) might occur at a much later point in time (Blunsdon et al., 2003: 52). This suggests that students usually experience state emotions first before they may experience trait emotions. These two types of emotions are also associated with experiential and reflective cognition (Rieber \& Noah, 2008). 'Experiential cognition is based on reactions to moment-to-moment event' (Rieber \& Noah, 2008: 80) whereas 'reflective cognition requires careful and deliberate though and consideration over time' (Rieber \& Noah, 2008: 80). Obviously, state emotions work with experiential cognition and trait emotions work with reflective cognition. Whether STEM students experienced either trait emotions or state emotions are also part of the investigation of students' enjoyment.

\section{Benefits of enjoyment}

Enjoyment seems to be associated with other benefits such as sense of achievement, concentration, enthusiasm, commitment, confidence, creativity, motivation, interest, persistence and satisfaction. Since the relationship between enjoyment and other benefits tend to be described using two or three states, this section summarises on how other benefits relate to enjoyment by comparing and combining multiple Venn diagrams which may consist of a few or more sets of different mental states. Please refer to the two big Venn diagrams on the page 3 and 4 .

1) Relation between concentration and enjoyment: Three new Venn diagrams (A, B and C) can be created using 1),2) and 3). In 1), a new Venn diagram A will be created. Concentration is an example of state emotions, which means present, current enjoyment. It also uses experiential cognition which is based on reactions to the moment-to-moment event. However, Crook \& Heath (2008) describes how concentration and enjoyments links as follows: 'finding pleasure in a learning task results in thinking hard, focussing...' (Crook Heath, 2008: 22) and 'enjoyment cannot be extricated from focus' (Crook Heath, 2008: 38). This can be described to Venn diagram A which consists of concentration and enjoyment. It also implies that concentration occurs after the enjoyment.

2) Relation between concentration and enthusiasm: In continuation from 1), a new Venn diagrams B can be created in 2). It was noted in $50 \%$ of Crook Heath's (2008) research, 'young learners reported enthusiasm co-occurring with a high level of focus (which is concentration)' (Crook - Heath, 2008: 
41), which can be described to Venn diagram B, consisting of concentration and enthusiasm.

3) Relation between enthusiasm and enjoyment: In the continuation from 1) and 2), a new Venn diagrams $\mathrm{C}$ can be created in 3). Related to enthusiasm, enthusiasm is also linked to enjoyment as 'enthusiasm plays a critical part in the formula of enjoyment' (Crook - Heath, 2008: 41) and 'enjoyment supplies the energy through enthusiasm' (Crook - Heath, 2008: 41) which can be described in Venn diagram $\mathrm{C}$, consisting of enthusiasm and enjoyment. Therefore, it is possible to combine Venn diagrams $\mathrm{A}, \mathrm{B}$ and $\mathrm{C}$ which consist of concentration, enthusiasm and enjoyment.

4) Relation between commitment and enjoyment: Setting aside the above (Venn diagrams A, B and C), concentration and enthusiasm, enjoyment also interlinks with commitment. Crook - Heath (2008) claims that 'enjoyment cannot be extricated from concentration and commitment to a task' (Crook Heath, 2008: 38) which can create a Venn diagram D, consisting of commitment and enjoyment.

5) Relation between motivation, interest and enjoyment: Four new Venn diagrams (E, F, G and $\mathrm{H}$ ) can be created using 5) and 6). In 5), three new Venn diagrams (E, F and $\mathrm{G}$ ) can be created. The first Venn diagrams $\mathrm{E}$ describes the relationship between interest and motivation and the second Venn diagram $\mathrm{F}$ describes the relationship between interest and enjoyment. Shernoff et al. (2003) also maintains that interest in an activity is a fundamental aspect of flow experiences, setting the foundation for continuing motivation (Shernoff et al., 2003: 161)', which can be described of Venn diagram which consists of interest and motivation (Venn diagram E). According to Blunsdon et al.'s (2003) definition of enjoyment, 'enjoyment is sometimes called "interest" (Blunsdon et al., 2003: 44), which can be described of Venn diagram, consisting of interest and enjoyment (Venn diagram F). 'The consistent findings within this research domain have been that individuals who report high interest and enjoyment of the task also evidence greater motivation for the task' (Remedios et al., 2000: 355). This confirms that it is possible to combines Venn diagrams $\mathrm{E}$ and $\mathrm{F}$, which is Venn diagram $\mathrm{G}$ showing the relationship among interest, enjoyment and motivation.

6) Relation between motivation, persistence and enjoyment: In continuation from 5), a new Venn diagrams $\mathrm{H}$ can be created in 6). According to Lumby (2011), 'the learning task is assessed potentially enjoyable, resulting in motivation to start and experienced as enjoyable, resulting in persistence' (Lumby, 2011: 10). This implies the possible relationships among enjoyment, motivation and persistence. It does not clearly show the link and therefore, it is not possible to describe them in Venn diagram. However, it is possible to an additional set 'persistence' between the 'motivation' and 'enjoyment' in the existing Venn diagram $G$ from 5), which makes Venn diagram $\mathrm{H}$, showing the link among persistence, motivation and enjoyment. 
7) Relation between satisfaction and motivation: Setting aside the above (Venn diagrams A-H), a new Venn diagram I can be created. Satisfaction is

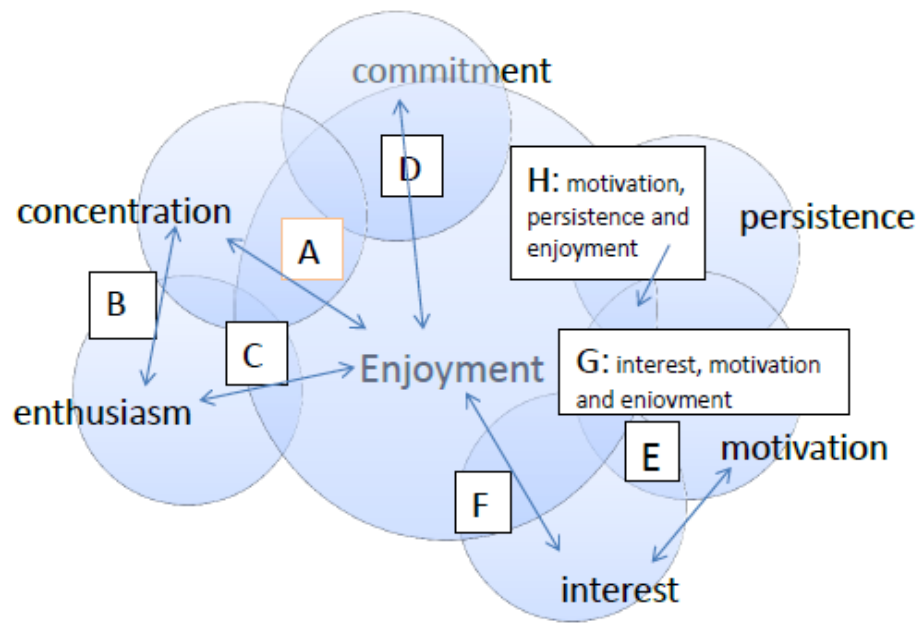

defined as 'an overall affective response to a perceived discrepancy between prior expectation and perceived performance' (Engel et al., 2000; Oliver: 252 1980). Csikszentmihalyi claims that 'people are motivated to pursue these activities because they derive some satisfaction from them' (Csikszentmihalyi, 1977: 13), which can be described to a Venn diagram I, consisting of motivation and satisfaction.

8) Relation between creativity, satisfaction and enjoyment: A new Venn diagram J can be created using 8). According to Csikszentmihalyi (1977), 'the flow experience can be found in activities other than games. One such activity is creativity in general' (Csikszentmihalyi, 1977: 37). So taking note of that flow activities are creative, the following statement shows the relationship among creativity, satisfaction and enjoyment: 'Flow activities, including intellectually demanding tasks, can also be enjoyable and satisfying. They may provide a feeling of creative accomplishment and satisfaction' (Shernoff et al., 2003: 161). Therefore, a new Venn diagram J can be created which consists of creativity, satisfaction and enjoyment.

9) Relation between sense of achievement and enjoyment: Three new Venn diagrams K, L and $\mathrm{M}$ can be created using 9), 10) and 11). In 9), a new Venn diagrams K will be created. Lumby (2011) concludes that a sense of achievement is also a source of enjoyment (Lumby, 2011: 16). Research suggests that at least one dimension of assessment of enjoyment may be how far expected achievement or grade were achieved (Remedios et al, 2000). This can be described Venn diagram $L$ which consists of a sense of achievement and enjoyment. In the report of Japanese language studies conducted in 2015, one of the questions asked was what students find most 
enjoyable about their current Japanese study course. One student commented: 'the sense of fulfilment to be able to converse in Japanese fluently is so rewarding! It's something that can't be replaced' (Japan foundation, 2016: 206). This comment may confirm the link between a sense of achievement and enjoyment.

10) Relation between a sense of achievement and satisfaction: In continuation from 9), a new Venn diagram L will be created in 10). According to Lumby (2011), 'young people reflected on their achievements and attainment with satisfaction' (Lumby, 2011: 27), which can be created Venn diagram L, consisting of a sense of achievement and satisfaction. Csikszentmihalyi (1990) claims that 'such feelings (i.e. a feeling of creative accomplishment and satisfaction) may occur mainly in retrospect because and creativity and satisfaction are trait emotions.

11) Relation between satisfaction, a sense of achievement and confidence: Further addition to Venn diagrams $\mathrm{K}$ and $\mathrm{L}$ in 9) and 10), confidence may be added. According to Crook \& Heath (2008), 'confidence... is associated with inner state and usually can be determined only through the learner's selfassessment of how he or she is moving toward satisfactory achievement of an outcome or goal' (Crook \& Heath, 2008, 25), which may be possible to position confidence links between satisfaction and achievement. Therefore, Venn diagram $\mathrm{M}$ describes the relationship among confidence, sense of achievement and satisfaction.

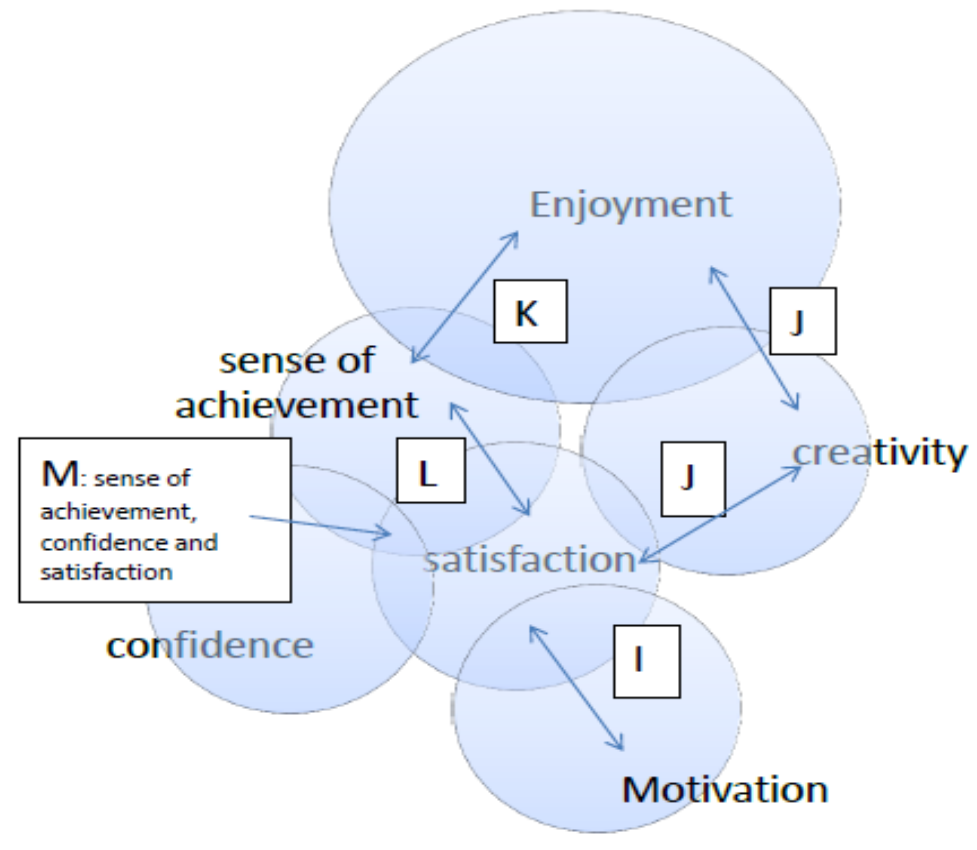


All 11 statements were combined and the benefit of enjoyment can be summarised with several combinations of Venn diagrams into two big Venn diagrams. According to these, enjoyment directly links to enthusiasm, concentration, commitment, motivation, persistence, interest, motivation, creativity and a sense of achievement. These mental states are the direct benefit of enjoyment. Indirect benefits of enjoyment include confidence and satisfaction. Satisfaction is only linked/experienced to motivation, creativity and sense of achievement, and is not directly linked/experienced to enjoyment from this summary. Similarly, confidence can be linked/ experienced to a sense of achievement and satisfaction. So, if learners said that they enjoyed learning, it is possible to say that they may experience other direct benefits of enjoyment in addition to the enjoyment. In other words, learners may also usually experience one or more or from the following combinations such as enthusiasm, concentration, commitment, motivation, persistence, interest, motivation, creativity and a sense of achievement simultaneously. Furthermore, learners may also experience indirect benefits of enjoyment such as confidence and satisfaction.

Triggers of enjoyment

From a study which investigate primary school pupils' enjoyment in collaboration with artists (dancers and musician) and their class teachers, 254 Crook \& Heath (2008) claim following three factors as triggers of enjoyment: i) focussed activity (concentration); ii) knowledge that someone else cares; iii) and praise from others. iv) ownership of their learning; v) role of creator and explorer and vi) enthusiasm also plays critical part in the formation of enjoyment.

Griffin's (2006) explores enjoyment and learning in Irish history and claims that David Manson (1726-1792) is 'one of the great pioneer of education in Ireland in the $18^{\text {th }}$ century' (Griffin, 2006: 133) and highlights his 'play school' (Griffin, 2006). His three 'pedagogy of enjoyment' are: 'i) teaching and learning is a process of partnership; ii) learning is closely linked to selfesteem building and fun utilising imaginative and playful method; iii) 'sense of belonging to a group' to have sense of achievement' (Griffin, 2006: 140); iv) satisfaction; and v) affirmation and praise (Griffin, 2006: 140). From these two scholars, both Crook \& Heath (2008) and Griffin (2006) agree on 'sense of belonging to a group' / 'knowledge that someone cares' and 'praise' which is a trait emotion. Other factors include mental states (satisfaction) and state emotions (concentration) which were discussed in the benefits of enjoyment.

However, Lumby's (2011) triggers of enjoyment should be taken note of, as the concept of flow is included which may provide further discussion. Lumby (2011) lists four triggers of enjoyment: i) flow experience; ii) cessation of anxiety control; iii) satisfaction; and iv) security of belonging. This means 
that flow is one part of antecedent of enjoyment. In other words, people usually experience flow first before they experience enjoyment. Lumby (2011) shares similar view with Csikszentmihalyi (1977), who created the concept of flow. He also claims that 'flow experience...is the crucial component of enjoyment' (Csikszentmihalyi, 1977, 11), which implies that flow is an antecedent of enjoyment. However, Shernoff et al. (2003) claim that 'concentration, interest and enjoyment must be experienced simultaneously in order for flow to occur' (Shernoff et al., 2003: 161). This implies that enjoyment is antecedent of flow, which is the opposite claim of Lumby (2011) and Csikszentmihalyi (1977). In this study, STEM students' enjoyment is assessed whether their enjoyment is with or without the presence of flow so that it may be able to determine whether flow is an antecedent of enjoyment or not.

Since the concept of flow was introduced in the discussion of enjoyment, the next section discusses the concept and triggers of flow, compared to those of enjoyment.

Flow: Definition and condition of flow

The founder of flow, Csikszentmihalyi's (1977) named 'the holistic sensation when people they act with total involvement' (Csikszentmihalyi, 1977: 36) as flow. This definition suggests that flow is difficult for the participants to experience themselves of their flow state which they are in. So asking this study's participants if they experience flow may not bring reliable results. However, Csikszentmihalyi (1977) suggests that three are six conditions of flow, which may be useful to assess whether the study participants have experienced flow or not. These are: 1) merging of action and awareness (Csikszentmihalyi, 1977: 38); 2) the tasks are within one's ability to perform (Csikszentmihalyi, 1977: 39); 2) centering of attention (Csikszentmihalyi, 1977, 40); 3) self-forgetfulness (Csikszentmihalyi, 1977: 42); 4) in control of his action and the environment (Csikszentmihalyi, 1977: 44); 5) coherent, noncontradictory demands for action and clear, unambiguous feedback (Csikszentmihalyi, 1977: 46); 6) need no goals or rewards external to itself (Csikszentmihalyi, 1977: 47). If a participant experiences one or more of these six elements, it may be possible to say that he/she experiences flow state. For this reason, some of Csikszentmihalyi's (1977) elements are included in the questionnaire to assess if the STEM students experience the flow state.

Flow also invokes a growth principle, which means that individuals seek to replicate flow experience once they experienced it: 'Once individuals master new challenges, they must identify progressively more complex challenges to create an ideal match for their skills' (Shernoff et al., 2003: 161). This is another indication that participants experience flow, which is also used in analising data to assess flow in this study.

Looking at recent flow study, some of Csikszentmihalyi's (1977) conditions have been removed or added. For example, Whitson \& Consoli (2009) 
identifies seven characteristic to attain flow: i) a challenging activity that require skills; ii) merging of action and awareness; iii) concentration on the task at hand; iv) clear goals and feedback; v) paradox of control; vi) the loss of self-consciousness; and vii) the transformation of time. On the other hand, Moneta (2012) considers that 'concentration, goals, feedback and balance are defined as antecedents of flow' (Moneta, 2012: 44). What seem to be the unchanged since Csikszentmihalyi's (1977) are concentration and feedback. Concentration is also a benefit of enjoyment which shares enjoyment and flow.

\section{Research methods \\ Questionnaire}

This research uses both quantitative and qualitative methods from Imperial and KCL's own evening course feedback sheets and also researcher's questionnaires. The data was analysed in two ways. Firstly, descriptive statistics derived from the STEM students' questionnaire suggested the percentage of STEM students in each question regarding enjoyment and flow. The descriptive statistics also derived from STEM students' frequency of experiencing enjoyment and flow was also used. Secondly, content analysis was carried out from those who left comments in the open-ended questions regarding why STEM students study Japanese and regarding enjoyment and flow experience. From this, a range of themes were discerned from the analysis of individual comment. These similar emerging themes were grouped together and then cross-referenced with the concept of enjoyment and flow to interpret the data. Exploring the questionnaire data allowed the explanation of STEM students to be compared to the differing concepts of enjoyment and flow uncovered in the first part of the paper. It also allowed consideration of whether STEM students' enjoyment and flow existed through Japanese language learning. The details of the questionnaire are explained under the three headings, i) the reason why STEM students study Japanese in addition to their major?, ii) enjoyment and iii) flow:

Why STEM students study Japanese in addition to their major?

This question was investigated by the following two questions: 1 . Why did you first decide to study Japanese? 2. What is the biggest influence to study Japanese? The first question is an open-ended question which allows students to express their own opinion. The second fixed-alternative questions consist of 11 choices which students can choose from as their influencing factors to study Japanese. These choices are:
a. Manga
b. Japanese technology
c. Japanese music/fashion
d. Japanese food
e. Visiting Japan
f. Japanese language on its own
g. Since I study STEM, it makes me want to stimulate my creativity

Slavonic Pedagogical Studies Journal, ISSN 1339-866o, Volume 5 Issue 2, September 2016 
h. I can get better marks in language compared to my major

i. I want to live/work in Japan

j. I have Japanese girlfriend/boyfriend

k. Other.

If any student chooses ' $\mathrm{k}$ Other', they had the opportunity to write their comment as other reasons.

Enjoyment

Students' enjoyment is assessed by two questions. The former is an indirect and the latter is a direct question: a) Do you wish to continue learning Japanese after this course? If so why? b) Is learning fun?

Flow

STEM students' experience of flow was investigated using Csikszentmihalyi's (1977) six flow experience statements. These seven statements include characteristics of flow and are descriptions/quotes by a professional basket player, dancer and a composer. These were:

Q1) During the class, has it ever crossed your mind 'What am I doing here?' 'Should I be doing this?'

Q2) When I am totally immersed in what I am doing, I don't think about anything else at all.

Q3) I feel in control of myself during the Japanese class.

Q4) My mind wanders during the class.

Q5) During the Japanese class, I have even temporarily forgotten my problems.

Q6) Studying Japanese is like a therapy.

Q7) I have felt that time passes a hundred times faster.

To answer the above seven statements, students were asked to choose and tick either 'often', 'sometimes' or 'never' as the frequency.

\section{Participants}

The total number of the all participants was 78 , and was a total of seven classes, of different language levels and a mixture of undergraduate, postgraduate and mature students from Imperial College London (total of 68 students, 6 classes) and KCL (total of 9 students, 1 class). The breakdown of Imperial College London participants was: one Imperial Horizon's level 1 class (16 students) and two Imperial Horizon's level 2 classes (13 students and 19 students), plus two evening classes (Japanese post-beginners, 7 students and Japanese intermediate class students, 7 students) and one summer term programme class (7 students). The students of three Imperial Horizons classes were undergraduate STEM students and those of the evening classes consisted of post graduate (master's program or $\mathrm{PhD}$ students) who currently study at Imperial or members of the public, majority of whom had previously studied STEM subject at Imperial or other universities. 
Although KCL is not a STEM university and it has a very small sample, it was decided to include in the data as 5 students out of 9 students are currently studying STEM or previously majored in STEM subjects. These students who were studying Japanese level 1 consisted of undergraduate students and members of the public.

\section{Procedure}

The questionnaires was administered and collected in the teaching week W19 for three Imperial Horizons undergraduate classes and on the teaching week W20 for the three evening classes at Imperial College London. The reason why W19 was chosen was due to the final exam in W20 on the Imperial Horizon's courses. At KCL, the questionnaires was administered and collected in the teaching week W10.

A letter to my students which explains my research intention was composed by the researcher. This letter along with the participation information sheets and the students' consent forms were given to the students on the W18 or W19. Students' consent forms were obtained prior to the researcher questionnaire on W19 or W20. Permission for the research from the Director of the Centre for Languages, Culture and Communication at Imperial and from the Research Office at KCL were both granted before the commencement of the research. The researcher was registered as a KCL researcher and its Research Ethics Number at KCL is MR15/16-217.

\section{Ethical issues}

The researcher ensured that the research was not detrimental to the class time for the students to learn Japanese and also ensured that students have the right for their voluntary participation and that they have the right to withdraw at any point without penalty and with no financial inducement. The confidentiality and anonymity of students' record is respected and protected in the research. The privacy of the participants was respected and students' anonymity and data were also protected.

\section{Research questions (RQs)}

RQ1. Why students study Japanese in addition to their major? What is the attraction of studying Japanese?

RQ2. Do students study Japanese because they enjoy the experience? If so, do they experience either trait emotion or state emotions, or both?

RQ3. Do students experience flow during Japanese lessons? If so, what mental or emotional states do they experience?

\section{Results}

Data was analysed under the three headings: 1) why STEM students study Japanese; 2) enjoyment and 3 ) flow, which will be summarised and discussed again using these three research questions in the Conclusions. 


\section{Why STEM students study Japanese in addition to their major?}

Why did you first decide to study Japanese?

A total of 21 different reasons were collected. About $26 \%$ of STEM students gave a reason as 'interest in Japan/Japanese culture/language which is an outstanding reason among the rest of the reasons. This reason matches Blunsdon et al.'s (2003) definition of enjoyment, which is 'interest' (Blunsdon et al., 2003: 44). It also shows that approximately a quarter of STEM students have already had an interest in Japan before they study the language, which is linked to enjoyment.

Following this, 'future plans' related to Japan ('I want to travel in Japan (7 students) and 'I want to do engineering/work in Japan' (3 students); 'I want to live in Japan' ( 1 student) and 'interesting/fun' (5 students) is one of top three reasons.

Quite a few students expressed their likings for things related to Japan (e.g. 'I like Japanese cartoons/anime/manga', 8 students; 'I like Japanese films and TV (4 students); 'I like medieval Japanese literature (1 student); and 'I love Japan/people/food/culture very much (5 students), which is also a strong influence. This reason also applies to Blunsdon et al.'s (2003) definition of enjoyment, which is 'expressed liking' (Blunsdon et al., 2003: 44). One STEM student has already established their enjoyment of Japanese language study and he considers Japanese learning his 'hobby'.

Other reasons for studying Japanese includes 'for the challenge' (1 student) and 'I want to learn a new language' (1 student). This reminds of flow's growth principle in that these students already experience flow and 'they must identify progressively more complex challenges to create an ideal match for their skills' (Shernoff et al., 2003: 161).

Other students decided to study Japanese because they thought that it was 'useful' and 'This course provide a good way to learn it while taking my degree' (3 students). The STEM students' Japanese learning in this study was in the context of IWLP, and some students also made positive comments of it.

Lastly, other students study Japanese because their close friends are Japanese (e.g. 'Japanese friend' (1 student) and 'Japanese girlfriend/boyfriend' (1 student)' and for her religion (e.g. 'I have a Japanese religion' (1 student).

What is the biggest influence to study Japanese?

The first three biggest influences were: 1. 'visiting Japan' (72\%); 2. 'manga' $(62 \%)$; and 3.'Japanese food' (49\%). Japanese music/fashion (29\%), Japanese foods (49\%) and Japanese technology (22\%) relates to Japanese culture and the majority of students seemed to choose these cultural reasons as the biggest influence to study Japanese. $38 \%$ of STEM students seem to study Japanese because of pure language study. A PhD student in Chemistry 
provided a comment about the Japanese language as follows: 'Japanese is unique. It sounds like a European language (easier to pronounce compared to Arabic and Chinese, but still 'look' beautiful/nice (non-Latin script).

There were not many STEM students who study Japanese for their credits $(8 \%)$ and students seems to study Japanese from their future plans or intentions (e.g. 'I want to live/work in Japan' or 'visiting Japan' (72\%) and from their own interests (e.g. Manga, Japanese technology, Japanese food, Japanese language on its own). Only $8 \%$ of STEM students chose the reason 'Since I study STEM, it makes me want to stimulate my creativity' and it seems that STEM students did not seem to consciously aware that language study is more creative than STEM subjects. 10\% of STEM students studied Japanese because of their Japanese friends/loved ones.

The comments which STEM students provided in 'other' offered content analysis and their comments were categorised in four themes. The first theme was that their close contact with the Japanese. Some students' reasons are related to 'I have Japanese girlfriend/boyfriend' such as: 'My boyfriend knows a bit of Japanese'; 'I want a Japanese friend'; 'My close friend is Japanese and even though her English is perfect, I want to be able to speak Japanese with her'; 'Not to be awkward with girlfriend's family in Japan'; and 'My boyfriend is Japanese'. The second theme was that their interest relates to Japan: 'A lot of code comes from Japan (especially in robotics) 260 very useful to know'; 'Japanese drama/movie'; 'I like Japanese culture/literature/architecture; 'Japanese cinema'; 'Japanese video games'; and 'Cultural interest- Language is key for learning about Japanese culture which is very unique'. The third theme was their future plan/intention may need the Japanese language knowledge: 'Japanese citizenship requires knowing Japanese'; 'It might be useful during my work in the future'; and 'I may move to Japan'. The fourth theme relates to students' desire, interests and benefits: 'I want to learn a second language'; 'I thought it would be fun'; and 'better career prospect'.

\section{Enjoyment}

Students' enjoyment in Japanese language learning

Students' enjoyment was assessed by two direct and indirect questions: a) Do you wish to continue learning Japanese after this course? If so why?; b) Is learning fun?

According to Theory of Planned Behaviour (Ajzen, 1991) and the Theory of Reasoned Action (Fishbein and Ajzen, 1975), 'behavioural intention can be a strong predictor of actual behaviuor' (Koufaris, 2002: 207). Koufaris (2002) also claims that 'intention to return' is a satisfactory approximation of actual customer retention' (Koufaris, 2002: 207). The first question a) which asks 'intention to return' may also indicate STEM students' enjoyment in Japanese learning. In the first question a), among 78 students, 71 students (91\%) answered to continue learning Japanese, i.e., 91\% STEM students

Slavonic Pedagogical Studies Journal, ISSN 1339-866o, Volume 5 Issue 2, September 2016 
enjoyed the Japanese learning experience. In question a), there is a further question which STEM students were asked to provide a reason. Six students answered that 'I enjoyed the class' or 'I like it'. This also shows their enjoyment of Japanese learning based on Blunsdon et al. (2003) definition of enjoyment, that is, "enjoyment is sometimes called... "expressed liking", (Blunsdon et al., 2003: 44). Related to this, two students described the intensity of their liking as 'really, enjoyed the course. I fall in love with the language' and 'I'm hooked'.

There are other reasons. Eleven students answered that they wish continue to study Japanese because 'I wish to improve' / 'My Japanese is not satisfactory' / 'I try to get better'. Similarly, 10 students answer that reason as 'I wish to become more fluent' / 'I'm not there yet' / 'little has learned' or 'I want to learn more'. 10 students answered that 'fun' or 'interesting'. This confirms that enjoyment is strongly linked to mental states such as 'fun' and 'interesting'. One student made comment: 'Fun + interesting + uses new parts of my brain'. Although it is claimed that 'all learning is accompanied with pain' (Davidson, 1990: 201) and 'schools, officers, factories are organised around the assumption that the serious work is grim and unpleasant' (Csikszentmihalyi, 1977: 1), the majority of STEM students considered that Japanese language learning was enjoyable rather than grim, painful and unpleasant. This may be because STEM major students do not study Japanese as their major subject and they may consider language learning as recreation relaxation or a change from their main studies. On the other hand, 5 STEM students answered that they did not wish to continue and 2 STEM students answered that they were unsure. One STEM student answered that 'I don't know whether I can handle the stress' which indicates that there was a student who considers that learning was grim, painful and unpleasant.

Continuing the rest of the reasons why they wish to study Japanese are: 4 students answered 'I like to learn' or 'I want to learn'. Four students answered 'useful' or 'beneficial'. Five students answered for their future intention of travelling / visiting to Japan. Four students answered that they wish to live/work in Japan, which is stronger commitment than travelling to Japan. Three students studied Japanese for cultural and technological reasons. Three students answered 'advanced level is attainable' or 'wish to achieve the next level'. This confirms the flow's growth principle, i.e., individuals seek replicate flow experience once individuals experienced flow: 'once individuals master new challenges, they must identify progressively more complex challenges to create an ideal match for their skills' (Shernoff et al., 2003: 161). This is evidence of their flow experience during the Japanese classes.

The second question b) asked directly if they enjoyed studying Japanese: 'Is learning fun?' 77 STEM students (99\%) ticked 'yes' and one STEM student ticked between 'yes' and 'no'. The result of both questions confirms that nearly all STEM students enjoyed. The result of second question was slightly 
lower than the first indirect question a) but perhaps some STEM students may not have provided an honest answer in the questionnaire in question b).

Trait emotions and state emotions

With regard to whether the enjoyment is specific class or cumulative experiences, $15 \%$ of STEM students ticked the statement 'the enjoyment of Japanese was the experience of a specific class' which is state emotion. On the other hand, $85 \%$ students ticked the statement that enjoyment of Japanese was the cumulative experiences, built over time. This suggests that enjoyment of Japanese language learning may be the cumulative experience rather than enjoyment of each class.

HAP associates with 'enthusiastic, excited, energetic' (Tsai et al., 2006, 290) and 'joy' (Kuppens, 2008: 1054). LAP is associated with 'calm, relaxed, serene' (Tsai et al., 2006, 290) content (Kuppens, 2008: 1054) and 'at ease' (Kuppens, 2008: 1057). The results showed that STEM students experienced 'excited and enthusiastic' (67\%) is the most strongly experienced state, followed by 'pleasant' (54\%), 'comfortable' (47\%), 'relaxed' (45\%), 'energetic' (37\%), 'powerful and warm feeling' (36\%), calm (32\%) and 'in control of myself' (26\%) the least. The first 'exited and enthusiastic' (67\%) and the fifth 'energetic' (37\%) are HAP associated emotions. From the second to the forth states ['pleasant' (54\%), 'comfortable' (47\%) and 'relaxed' (45\%)] are LAP associated emotions. It seems that there are more 262 LAP associated emotions among the STEM students, which can be explained that the majority of STEM students were undergraduate students who came from collectivist countries and their preferences were indicated. Although dominant states are LAP associated emotions, the first (excited and enthusiastic, 67\%) is HAP, which is preferred by individualist culture. This indicates that 'excited and enthusiastic' may be universal emotion regardless of individualist or collectivist culture. 'Relaxed' (45\%) and 'comfortable' $(47 \%)$ indicates a similar percentage, which was an anticipated outcome as they are both LAP emotions. 'Energetic' (43\%) is a HAP associated emotion and was expected to have similar percentage as 'excited and enthusiastic' $(67 \%)$, but it was about half of 'excited and enthusiastic'. 'Calm' (32\%) was expected to have the similar percentage as 'relaxed' (45\%) and 'comfortable' $(47 \%)$, but it turned out to be a lower percentage.

\section{Students' flow experience}

Q1) During the class, has it ever crossed your mind 'What am I doing here?' 'Should I be doing this?' (Csikszentmihalyi, 1977: 38).

Csikszentmihalyi's (1977) first characteristic of flow is merging of action and awareness. This statement is used to assess whether STEM students merged of action and awareness during the class to experience flow. $64 \%$ of STEM students ticked 'never', 29\% of STEM students ticked 'sometimes' and 6\% of STEM students ticked 'often'. This result shows that more than half (64\%) of the STEM students were able to experience flow which merged of their action and awareness. 
Q2) When I am totally immersed in what I am doing, I don't think about anything else at all.

This is another statement to assess the merging of action and awareness and is a quote from a dancer when he says 'You are totally involved in what you are doing' (Csikszentmihalyi, 1977: 39). 49\% of STEM students ticked 'sometimes', 44\% STEM students ticked 'often' and 8\% STEM students ticked 'never'. According to this result, 92\% of the STEM students experienced the flow.

Q3) I feel in control of myself during the Japanese class.

Csikszentmihalyi's (1977) second characteristic of flow is 'in control of actions and of the environment' (Csikszentmihalyi, 1977: 44). This statement is used to assess whether STEM students felt in control of their actions and experienced flow during their Japanese classes. According to Beveridge \& Milner's (2006) study, students who 'in control of their learning were more focused and had a more valuable learning experience' (Whitson \& Consoli, 2009: 44). It is also claimed that student-centred activities also contribute to a sense of student control over learning (Whitson - Consoli, 2009). Among the participants, 62\% STEM students ticked 'often', 36\% STEM students ticked 'sometimes' and 2\% STEM students ticked 'never'. This result shows that $98 \%$ of the STEM students felt in control of their Japanese learning to experience flow, which suggests that these students were more focused and had a more valuable learning experience.

Q4) My mind wanders during the class.

According to Csikszentmihalyi (1977), flow occurs 'when tasks are within one's ability to perform' (Csikszentmihalyi, 1977: 39), which is the third characteristic of flow. This statement was quoted from a dancer when he said 'Your mind isn't wandering' (Csikszentmihalyi, 1977: 39), which is also used to assess whether STEM students felt their tasks are within their ability to perform' to experience flow during their Japanese classes. 51\% students ticked 'never', 37\% students ticked 'sometimes' and 12\% students ticked 'often'. This result shows that approximately half of the STEM students experienced the flow and they felt that the challenges during the class were within their ability to perform. In contrast, over $10 \%$ of STEM students often found that the challenges or tasks were too great for their ability but achievable.

Q5) During the Japanese class, I have even temporarily forgotten my problems.

Csikszentmihalyi's (1977) fourth characteristic of flow is 'centering attention' (Csikszentmihalyi, 1977: 40). In other words, it is concentration. To assess STEM students' concentration to experience flow during their Japanese classes, 'temporarily forgotten my problems' (Csikszentmihalyi, 1977: 48) was used. 50\% STEM students ticked 'sometimes', 32\% STEM students ticked 'often' and 18\% STEM students ticked 'never'. About $83 \%$ of STEM students were able to concentrate enough to experience flow during 
the class. In addition, content analysis also contributed to a STEM students' description of flow experience related to Q5). A PhD student in Computer Science described her flow experience as follows: 'When I study Japanese, I enjoy learning a new language and forgetting about my research and problems'. This student's flow experience reminds us of Csikszentmihalyi's (1977) description of a basket player's flow experience: 'Sometimes on court, I think of a problem, like fighting with my steady girl, and I think that's nothing compared to the game. You can think about a problem all day but as soon as you get in the game, the hell with it!' (Csikszentmihalyi, 1977: 41).

Q6) Studying Japanese is like a therapy.

This was a quote from a dancer who said 'dance is like therapy' (Csikszentmihalyi, 1977: 41), which was used to assess concentration. 46\% STEM students ticked 'sometimes', 27\% STEM students ticked 'often' and $27 \%$ STEM students ticked 'never'. About 73\% of STEM students answered that studying Japanese is like a therapy. Both Q5) and 6) ask concentration and the results for Q5) and 6) may be considered fairly similar.

Q7) I have felt that time passes a hundred times faster.

Csikszentmihalyi's (1977) fifth characteristic of flow is 'self-forgetfulness' (Csikszentmihalyi, 1977: 42). This statement was quoted by a chess player when he said 'time passes a hundred times faster' (Csikszentmihalyi, 1977: 44), which was also used to assess whether STEM students have experienced 264 forgetting themselves to experience flow during their Japanese classes. 55\% STEM students ticked 'sometimes', 27\% STEM students ticked 'often' and $18 \%$ STEM students ticked 'never'. $82 \%$ of STEM students felt the time passes faster to experience flow.

\section{Conclusions and discussions}

Reviewing the research questions will enable to summarise as the key conclusions of this study.

RQ1. Why students study Japanese in addition to their major? What is the attraction of studying Japanese?

Interest (in Japan/Japanese culture/language) is the most common reason for students to study Japanese and one in five STEM students in this study decided to study for this reason. This justifies Blunsdon et al. (2003)'s definition of enjoyment including interest (Blunsdon et al., 2003: 44). Quite a few students expressed their likings for Japanese culture including anime, manga, film, TV, literature, people, food, and country (e.g. Manga, Japanese technology, Japanese food and Japanese language on its own). This also justifies Blunsdon et al.'s (2003) definition of enjoyment which includes 'expressed liking' (Blunsdon et al., 2003: 44). Some STEM students decided to study Japanese because of 'the challenge', 'because of IWLP' or 'their Japanese friends'. 
There were not many STEM students who study Japanese for their credits but students seemed to study Japanese for their future plans or intentions (e.g. 'I want to live/work in Japan' or 'visiting Japan').

The comments which STEM students provided in the open-ended question showed four themes: the first theme is their close contact is the Japanese; the second theme is that their interest relates to Japan; the third theme is their future plan/intention may need the Japanese language knowledge; and the fourth theme relates to students' desire, interests and benefits.

RQ2. Do students study Japanese because they enjoy the experience? If so, do they experience either trait emotion or state emotions, or both?

Two direct and indirect questions were asked whether they enjoyed the Japanese learning, that is, a) Do you wish to continue learning Japanese after this course? If so why? and b) Is learning fun. With regards to the first indirect question, $91 \%$ of STEM students answered that they enjoyed studying Japanese. With regards to the second direct question, 99\% of STEM students answered that they enjoyed studying Japanese. From these results, it is possible to say that more than $90 \%$ of STEM students truly enjoyed studying Japanese. Some STEM students clearly stated in the questionnaire that they enjoyed the class.

Eleven STEM students' reasons for continuing Japanese was 'further improvement'. This mirrors one student's answer from a report on Japanese studies survey conducted by Japan foundation in 2015. One of their questions asked what students find most enjoyable about their current Japanese studies course. To answer this question, one student's comment was: 'being able to make a noticeable improvement in my knowledge of the Japanese language and understanding of Japanese culture as I continue to study' (Japan foundation, 2016, 206). Perhaps, another trigger of enjoyment may include 'improvement'. On the other hand, 2 STEM students' reasons for continuing Japanese were 'wish to achieve next level' and 'advanced level is attainable', which implies that the challenge was not too great for the task and achievable.

With regard to whether the enjoyment is specific class (state emotions) or cumulative experiences (trait emotions), 15\% STEM students ticked for state emotions and $85 \%$ students ticked for trait emotions. As it was mentioned earlier, state and trait emotions are associated with reference to experiential cognition and reflective cognition (Rieber \& Noah, 2008). Norman (1993) claims that both experiential cognition and reflective cognition are important and interdependent, but so does state emotions and trait emotions. People tend to use experiential cognition than reflective cognition in games, and Norman (1993) encourages using reflective cognition more. Perhaps this point may be Japanese language teachers' new challenge for students' enjoyment in learning so that students will be able to experience both state or trait emotions during their language learning. 
RQ3. Do students experience flow during Japanese lessons? If so, what mental or emotional states do they experience?

Flow experience was investigated by five key points in seven statements: 1) merging of action and awareness; 2) in control; 3 ) the tasks are within one's ability to perform; 4) concentration; 5) self-forgetfulness. The first point was explored by the first two sentences. $64 \%$ ticked the first statement which asked if STEM students have never crossed their mind 'what am I doing here? Should I be doing this?', which shows that they experienced flow. In the second statement 'what I am totally immersed in what I am doing, I don't think about anything at all', more than 90\% STEM students ticked either 'sometimes' and 'often' which indicates in flow state. The percentage difference between two statements was large and need to look at other statements for conclusion.

The second point ('in control') was explored by the third sentence, which is 'I feel in control of myself during the Japanese class'. Those who ticked either 'often' or 'sometimes' are considered to experience flow. The results show that $98 \%$ experienced flow state. This is similar percentage of the second statement.

The third point ('the tasks are within one's ability to perform') was explored 266 by the fourth sentence, which is 'My mind wanders during the class'. Those who ticked either 'never' are considered to experience flow. The results show that $51 \%$ did so and experienced flow state. $51 \%$ flow experience is similar percentage of the first statement, which was $64 \%$.

The fourth point (concentration) was explored by the fifth and sixth sentences, which is 'During the Japanese class, I have even temporarily forgotten my problems' and 'studying Japanese is like a therapy'. Those who ticked either 'often' or 'sometimes' are considered to experience flow. The results show that $83 \%$ and $73 \%$ experienced flow state respectively in fifth and sixth sentence.

The fifth point (self-forgetfulness) was explored by the seventh sentence, which is 'I have felt that time passes a hundred times faster'. Those who ticked either 'often' or 'sometimes' are considered to experience flow. The results show that $82 \%$ experienced flow state. $82 \%$ flow experience is very similar percentage to the fifth statement.

Overall, flow percentage seems to fluctuate based on the flow key words and statements. For example, the percentage of 'in control' is the highest (98\%), which is followed by 'merging of action and awareness' (92\%), 'concentration' (83\%) and 'self-forgetfulness' (82\%). The lowest percentage was 'the tasks are within one's ability to perform' (51\%). As for 'merging of action and awareness', there are two different responses among the students, 
which was $90 \%$ and $64 \%$. However, STEM students seem to experience consistently more than $50 \%$, which indicates more than half of the students are considered to experience flow consistently in the class. Comparing this flow result and high students' enjoyment results (more than 90\%), it may be able to conclude that flow is an antecedent of enjoyment. It is also noted that both enjoyment and flow share 'concentration' as condition of flow and as benefit of enjoyment.

To describe the mental states of STEM students experiencing flow, HAP and LAP were used, which can also demonstrate individualist and collectivist culture. HAP associates with 'enthusiastic, excited, energetic and joy' and LAP is associated with 'calm, relaxed, serene, content and at ease' (Tsai et al., 2006 and Kuppens, 2008). HAP associated emotion, 'excited and enthusiastic' $(67 \%)$ was the top of the states when the STEM students experienced flow, which suggest that 'excited and enthusiastic' may be universal emotion regardless of individualist or collectivist culture. 'Energetic' (43\%) was also expected to have similar percentage as 'excited and enthusiastic' (67\%), but it was about half of 'excited and enthusiastic' $(67 \%)$. A similar number of students ticked two LAP emotions 'relaxed' (45\%) and 'comfortable' (47\%) which is the second and the third states. 'Calm' (32\%) was expected to have the similar percentage as 'relaxed' and 'comfortable', but it was a lower percentage.

\section{Implications}

The result of this study suggest three implications. Firstly, it is possible to change the general assumption in learning from negative (grim and unpleasant or accompanying pain to enjoyment) to positive (enjoyable). The results of the questionnaire shows that the majority of students enjoyed studying Japanese and some students experienced flow and other states such as 'fun' or 'interesting', 'excited and enthusiastic'(HAP emotions) and 'relaxed' and 'comfortable'(LAP emotions). This leads to the second implication for the language teachers. If language teachers were able to manipulate and invoke flow among their students, students will consider language learning as same as leisure activities such as games, shopping or hobbies. In fact, Japanese language learning can become one's hobby as one STEM student answered that Japanese is his 'hobby' in the questionnaire. This leads to the third implication for the language teacher's professional practices. Language teachers should be informed and familiar with the concept of enjoyment and flow so that they can manipulate and invoke flow among the students. If the majority of language teachers were successful to invoke their students' enjoyment, it will not be long before the day will come when language learning will be established as the same as games and shopping, then language learning becomes more popular and promoted than ever before.

\section{Limitations and suggestion for future research}

As for limitation, the generalisation of the findings of the study may be limited. Since the findings of this study are the result of specific participants 
(IWLP context, STEM students and Japanese language learning), it may not to be able to generalise for other languages or Japanese learning in other countries. In addition, a few limitations of methodology (use of questionnaire) should be addressed. In developing the questionnaire, the researcher inferred and included the potential answers for participants' choices. However, a full understanding of students' perception and feeling may not necessarily be gained from the questionnaire because the options included by the researcher ma have limited the responses. Furthermore, there is always a danger that participants may not provide their honest opinion in the questionnaire, which relates to participants bias. On the other hand, researcher's bias should also be noted in interpreting open-ended questions, which may have applied in this study, i.e. difficulty in obtaining the unanimous interpretation. With regards to suggestion for future research, similar studies in different languages instead of Japanese may be of interest as a comparative study. This type of future research may also contribute to establish the positive general assumption on language learning and to disseminate more successful language teaching and learning which incorporates enjoyment.

\section{Bibiographic references}

AJZEN, I. 1991. The theory of planned behaviour. Organizational Behavior and Human Decision Process, vol. 50 n. 2. pp. 179-211.

ASSOCIATION OF UNIVERSITY LANGUAGE CENTRE (AULC). 2016. UCML-AULC survey of Institution-Wide Language Provision in universities 268 in the UK (2015-2016). Available online (accessed 07/8/2016): http://www.aulc.org/documents/UCML_AULC_2015-2016.pdf

BEVERDIGE, D.A. - MILNER, J. 2006. Flow theory in the English classroom. Studies in Teaching 2006 Research Digest. Research projects presented at the Annual Research Forum: Wake Forest University, WinstonSalem, NC.:(ERIC Document Reproduction Service No. ED494888)

BLUNSDON, B. Reed, K. - MCNEIL, N. 2003. Experiential Learning in Social Science Theory: An investigation of the relationship between student enjoyment and learning. Journal of Further and Higher Education, vol. 22, n.1, pp. 93-56. DOI: 10.1080/0729436032000056544

CSIKSZENTMIHALYI, M. 1977. Beyond boredom and anxiety, 2nd printing. San Francisco: Jossey-Bass.

CROOK, E. - HEATH, S. B. 2008. Finding Enjoyment, Gaining Achievement - a participatory research study. Doncaster Community Arts. Available online (accessed 27/6/2016): http://www.thepoint.org.uk/media/uploads/article/109/4fda02f7221e8Researc $\mathrm{h}$ into_links_between_enjoyment_and_achievement.pdf

DAVIDSON, T. $19 \overline{0}$. The history of education. London: Archibald Constable. ISBN: 987-0404019457.

FISHBEIN, M. - AJZEN, I.1975. Belief, Attitude, intention, and Behavior: An introduction to Theory and Research. Reading, MA: Addison-Wesley Publishing Co. ISBN: 9780201020892

ENGEL, J. F. - BLACKWELL, R.D. - MINIARD, P.W. 2000. Consumer behaviour $\left(9^{\text {th }}\right.$ ed.). Chicago, IL: Dryden Press. ISBN: 978-0030211089. 
GOETZ, T. - NATHAN, C. - HALL, A. C. - FRENZEL, A. - PEKRUN, R. 2006. A hierarchical conceptualization of enjoyment in students. Learning and Instruction, vol. 16, pp. 323-338.

GRIFFIN, S. 2006. Teaching for enjoyment: David Manson and his 'play school' of Belfast. Irish Educational Studies, vol. 24, n. 2, pp. 133-143. ISSN: ISSN-0332-3315

JAPAN FOUNDATION. 2016. Japanese studies survey 2015 - A survey of Japanese studies at university level in the UK. London. Available on line (accessed 27/6/2016): http://www.jpf.org.uk/download/Japan-FoundationJapanese-Studies-Survey-2015-Report.pdf

KOUFARIS, M. 2002. Applying the technology acceptance model and flow theory to online consumer behaviour. Information Systems Research, vol. 13, n. 2, pp. 205-223. DOI: 10.1287/isre.13.2.205.83

KUPPENS, P. 2008. Individual differences in the relationship between pleasure and arousal. Journal of Research in Personality, vol.42, pp. 10531059.

LUMBY, J. 2011. Enjoyment and learning: Policy and secondary school learners' experience in England. British Educational Research Journal, vol. 37, n. 2, pp. 247-264. DOI: 10.1080/01411920903540680

MONETA, G.B. 2012. On the Measurement and Conceptualization of Flow. In Engeser, S. (2012) (ed.), Advances in Flow Research. Springer: N.Y, pp. 23-50. ISBN: 978-1-4614-2358-4.

NEUMANN, R. - Parry, S. - BECHER, T. 2002. Teaching and learning in their disciplinary context: A conceptual analysis. Studies in Higher Education, Vol. 27, pp. 405-417. DOI:10.1080/0307507022000011525

NORMAN, D.A. 1993. Things that make us smart: Defending human attributes in the age of the machine. Reading. M.A.: Addison-Wesley Publishing Co. ISBN: 978-0201581294.

OLIVER, R. 1980. A cognitive model of the antecedents and consequence of satisfaction decision. Journal of Marketing Research, vol. 17, n. 4, pp. 460469. DOI: $10.2307 / 3150499$

REMEDIOS, R. - LIEBERMAN, D.A. - BENTON, T. G. 2000. The effects of grades on course enjoyment: Did you get the grade you wanted? British Journal of Educational Psychology, vol. 70, pp. 353-368.

RIBER, L.P. - NOAH, D. 2008. Games, simulations, and visual metaphors in education: Antagonism between enjoyment and learning. Educational Media International, vol. 45, n. 2, pp. 77-92.

SHERNOFFF, D.J. - CSIKSZENTMIHALYI, M. - SCHNEIDER, B. \& SHERNOFF, E.S. 2003. Student engagement in high school classroom from the perspective of flow theory. School Psychology Quarterly. vol. 18, n. 2, pp. 158-76. Available online (accessed 07/8/2016): http://www.cedu.niu.edu/ shernoff/pdf/shernoff.spq.pdf

TSAI, J.L. - KNUTSON, B. - FUNG, H. 2006. Cultural Variation in Affect Valuation. Personality Processes and Individual Differences, vol. 90, n. 2, pp. 288-307. DOI:10.1037/0022-3514.90.2.288

WHITSON, C. - CONSOLI, J. 2009. Flow theory and student engagement. Journal of Cross-Disciplinary Perspectives in Education, vol. 2, n. 1, pp. 4049. Available on line (accessed 07/8/2016): 
http://jcpe.wmwikis.net/file/view/whitsonconsoli.pdf

YOUNG, P. 2010. Generic or discipline-specific? An exploration of the significance of discipline-specific issues in researching and developing teaching and learning in higher education. Innovations in Education and Teaching International, vol. 47, n. 1, pp. 115-124. DOI: $10.1080 / 14703290903525887$

Dr Junko Winch

Imperial College London

Sherfield Building

Level 3

South Kensington Campus

London

SW7 2AZ

United Kingdom

j.winch@imperial.ac.uk 